\title{
POVERTY AND THE ORDINARY LAW: INTRODUCTION
}

\author{
Danie BRAnd ${ }^{*}$ and Karin VAn Marle ${ }^{* *}$
}

During 2012 a research project on the relationship between law and poverty, titled Poverty and Justice, was launched in the Faculty of Law of the University of Pretoria. The starting point and broad background to the project is the assertion that poverty is an injustice and the implicit flipside of that claim, that justice is the absence of poverty. The basic contention of the project is that any view of poverty as a practical social problem in the first place, rather than a manifestation of injustice, results in an approach to poverty that is focused solely on technical and managerial solutions. This kind of approach to poverty is problematic as it obscures the political dimensions of poverty, that is, the fact that poverty is embedded in and arises from a particular ideology. If one defines poverty as inadequate access to basic living resources such as housing, food, water and health care the political dimensions of poverty are brought to the fore. What determines access to these basic resources is economic and political power. Any response to poverty must therefore engage with and take account of power.

A prime example of the negation of the influence of power and politics in the creation and maintenance of poverty is the way in which the role of law with respect to poverty is conceptualised and presented. Law in the context of poverty is often seen and used as simply a policy instrument, as only regulation meant to give effect to policy choices and ensure fairness in the implementation of those choices. Alternatively, law in the form of the Constitution of the Republic of South Africa, 1996, is seen as a benign formative framework for development of policy. However, at its core, law expresses and reflects ideology and power. The basic rules of property, transaction, liability and procedure that regulate everyday life determine access to basic resources and so simultaneously create and maintain inequalities and power imbalances - law 'stands between availability and entitlement'. Any engagement with the role of law in the context of poverty must in the first place take account of the ways in which law creates and maintains poverty.

One of the specific aims of the research project is to investigate in a transdisciplinary way the nature, operation and effects of specific areas of our law (property law; contract law; procedural law; labour law; international trade law etc) with respect to poverty, to identify ways in which those areas of law might contribute to the maintenance of poverty and fashion ways in which they might be adapted to facilitate access to basic resources instead. 
In furtherance of this aim a seminar titled Poverty and Justice was held at the University of Pretoria on 17 and 18 October 2012. Papers were presented from a range of disciplines and sectors, including law, philosophy, sociology and on a range of topics, including housing, basic services, disability, labour, equality and public interest legal practice. Seven of the articles included in this Special Issue are a selection of the papers presented at this seminar. The remaining two articles, by Serges Kamga and Michael Dafel, as well as the case note by Tracy-Lynn Humby, are not drawn from the material presented at the seminar. However, the topics covered in them, viz. sanitation, housing and mining and municipal planning, are an appropriate fit with the broad themes explored in the seminar. 